\title{
Framework of China and Europe Green Financing for Sustainable Development
}

\author{
LI Miaoyan \\ State Administration of Taxation, Beijing, China
}

\begin{abstract}
It is estimated that about 50 percent of China's annual gross domestic product (GDP) is needed to compensate the environment cost, it is urgent to shift China's massive economy to green one. In China's 13th Five-Year plan (2016-2020), China plans to establish the "ecological civilization", incorporating air pollution control, energy consumption control targets, and green finance, laying out China's transition towards a green and low-carbon economy. However, the green finance system establishment demands many auxiliary systems, such as fiscal support, legal institutions, and other taxation aids. From global perspective, the green finance system also helps to reduce the environmental risks worldwide both the countries along ancient silk roads and the European countries. On the other hand, investment in Europe has still not recovered from pre-financial crisis levels. The European Union has to massively accelerate investment to meet its climate and energy obligations with an annual investment gap of $€ 100$ billion in funding Europe's energy infrastructure to reach its climate and energy targets. The European Union plans to re-boot the Capital Markets Union to help meet this challenge by setting up an expert group on sustainable finance. Both China and Europe are facing the climate challenge and they have to deal with it together. Chinese government advocates public-private partnership (PPP) model to improve the funding environment and actively seek way out. This paper aims to arouse the awareness of cooperation in Europe and China in green financing and hi-tech field, by creating a framework to improve the financing mechanism of environmental protection and green economy.
\end{abstract}

Keywords: green financing, green PPP, China-EU cooperation framework

\section{Introduction}

The world is increasingly faced with the challenges stemming from the need to sustain an expanding global population while simultaneously addressing the environmental pressures that could threaten our ability to accomplish this. Green growth has emerged as a strategy to balance the historically divergent priorities of achieving economic growth and social development without putting at risk the environmental systems and natural capital we rely so heavily upon. This approach emphasizes the environmental and economic gains achieved by reducing inefficiencies in the management of resources and the stimulation of new sources of activity through innovation and green market growth.

Green finance, which is key to eco-environmental protection and the development of a green economy, has become a global trend. Since the development of green finance has significant role to protect the ecological environment and accelerate economy, and develop the financial industry, so green finance (ecological finance 
or sustainable financing) is an important tendency to develop modern financial industry.

Green finance is also the necessary way to balance the relationship among economy, society, and environment, and to satisfy the needs for sustainable development. ${ }^{1}$ As one of special financing method, green public-private partnership (PPP) is that combines the government fiscal support with market private capital to invest many green schemes. The last 20 years have seen the rise to power of PPPs as a means of crowding in investment and expertise from the private sector for the delivery of public works and services. Widely utilized because of their purported advantages in off-budget funding, PPPs are a mechanism that modern governments regularly turn to in the fulfilling of their responsibilities on public.

Green PPPs are yet to deliver on its potential for long-term sustainability and that a substantial rethinking of the business and contracture models are needed to ensure that it moves in this direction in the future. This includes not only a greater integration of sustainable procurement and sustainable investment principles into PPP agreements and contracting processes, but also a consideration of the potential for PPP procurement to serve as a vehicle and catalyst for green growth across many sectors of the economy.

This paper attempts to seek common ground of green financing (especially green PPP) for China and Europe cooperation.

\section{Importance of Green Financing for China and Europe}

As a market-based institutional arrangement, green finance plays an important role in the promotion of environmental protection and building of an ecological society. Green financing, according to new data developed through the DRCFI-led research launched at the China Development Forum, has increased at an annual growth rate of 23 percent in the five years to 2012, to about $\$ 260$ billion in 2012, equivalent to more than 2 percent of GDP.

\section{Importance of Green Financing for China}

First of all, China's natural environment is in a danger. China has witnessed rapid development over the past 30 years to become the world's second-largest economy, but at a steep environmental cost. It is estimated that about 50 percent of China's annual GDP is needed to compensate the environment cost. Some 20 percent of agricultural land is toxic to human health.

Up to 1 million people die prematurely each year as a result of air pollution, with lung cancer rates increasing by almost 500 percent in the past three decades. Those concerned with climate change know that nothing can be fixed unless pollution is dramatically reduced, and those focused on international developments understand the importance of greening China's rapidly growing outward investment. To combat environmental woes, China has made great efforts to transform its economic growth pattern into a more sustainable, green, and low-carbon model. Second, China's green industry drives green investment in key green sectors. It is estimated that there are at least about $\$ 460$ billion per year from 2015 to 2020 , or about $\$ 2.8$ trillion need to be invested in green industry from now to 2020. Two thirds of this will need to come from domestic and international financial and capital markets, given fiscal limitations and priorities.

It is estimated that China's green industry will call for an annual investment of about 2.9 trillion yuan (US\$0.47 trillion) between 2015 and 2020, which means a large amount of investment is needed for

\footnotetext{
1 Ying Shi: The research on strategies of China's Green Finance Development, National Conference on Information Technology and Computer Science (CITCS 2012).
} 
environmental protection and restoration, and fiscal inputs alone are far from enough to satisfy such needs. It is estimated that only 10 to 15 percent of the total sum will come from the government, and the rest should be channeled from the social sector. Against this backdrop, a systematic green financial system-a series of market-based institutional arrangements-should be established to stimulate green investment through a full array of financial products and services, including green loans, bonds, stocks, private equity, insurance, and carbon emissions trading. While confronted with mounting local government debt and a pressing need to fund urbanization, China is looking at a new style of finance to leverage private capital which is called officially as green PPP.

Third, China is establishing a green financing mechanism to facilitate the economy's transition to sustainable growth. Green growth is now part of China's development strategy and the demands for green financing keep growing as China enters a critical period for economic restructuring in China, a Green Finance Task Force was tasked to develop policy, regulatory, and market-innovations that would better align China's financial system with the needs of green industry and sustainable development. The context of this prioritizing of greening China's financial system is an important part of China's roadmap to "eco-civilization", which marks a major shift in its economic strategy towards a focus on greening the economy and broader aspects of China's development, after more than 30 years of rapid economic growth that has created a legacy of environmental challenges.

\section{Importance of Green Financing for Europe}

Europe is currently faced with a dual challenge of addressing pressing sustainability issues (including climate change-related targets), while at the same time overcoming a persistent low-growth trap. The EU has pledged to reduce emissions (relative to 1990 levels) by at least $40 \%$ by 2030 and at least $60 \%$ by 2040 . The EC estimates that up to $€ 2$ trillion will be required to meet the policy goals of the Europe 2020 Strategy for smart, sustainable, and inclusive growth, with more recent communications highlighting the need to enhance the wider framework for sustainable finance. In October 2015, the EC released its annual 2020 time frame.

In the wake of the financial crisis, a focus on systemic risk led to the implementation of new regulatory frameworks for banking, insurance, and investment. Now, European institutions and organizations are advancing the agenda on climate risk, including stranded carbon assets. Over the last two years, financial institutions and regulators have put their focus on these issues, with significant momentum building up to Paris Climate Conference (COP21) in December 2015. Multiple initiatives are currently underway within the European Commission level relevant to sustainable finance-but these issues have not yet been considered at a strategic level.

\section{The Analysis of Green Financing Development in China}

The International Finance Corporation (IFC) ushered in China the robust development of the carbon finance market and the emergence of innovative financial products including green bonds, green shares, green insurance, and green funds, all feature an increasingly wider and deeper integration between finance and environmental protection. As evidenced by the practices of developed countries over the past few decades, once properly designed systems are in place, the green finance system can effectively steer large amount of private capital toward green industry and significantly reduce the fiscal pressures of environmental management ${ }^{2}$.

\footnotetext{
${ }^{2}$ People's Bank of China: United Nations Environment Programme: Establishing China’s green financial system, April, 2015.
} 


\section{The General Green Financing Condition in China}

To further bolster China's sustainable economic and social development, the Chinese government has carried out a new round of comprehensive reform since 2013. The Chinese government has set key priorities, including reinforcing the rule of law, giving play to the decisive role of the market in resource allocation and establishing a modern state governance system and enhancing capacity.

China has so far developed guidelines and a statistical reporting system for green lending thanks to the government's work on green credit. Seven regions throughout the country have also launched pilot carbon emissions trading programs. ${ }^{3}$ These new systems allow financial institutions to consider the environmental impact of investment projects and the environmental protection records of businesses prior to granting loans. The central bank is drafting a directive concerning the issue of green finance bonds on the interbank market with the aim to make corporate credit bonds greener. These efforts aim to encourage social capital to shift away from high-polluting and high-energy-consuming industries toward energy-efficient, environmentally friendly, and green industries.

As an innovative management pattern of public goods and services provision, the PPP model has been broadly applied in China. In public service, anything that can be properly managed by the market should be open to social capital or corporate partners. The Chinese government has acted more as a policy-maker and market regulator, and let the corporate partners take more initiative and be more innovative. PPP is a reform to China's existing systems and mechanism. It has coordinately pushed forward there forms of the administrative system, fiscal system, investment, and financing mechanism. PPP is now a major element of the current supply-side structural reform and a component of deepening the reform in all rounds.

\section{The PPP Green Financing Situation in China}

Since 2014, the Chinese government has made initial achievements in advancing the PPP development in a systemic, integrated, and coordinated way. In 2015, the Ministry of Finance issued the Circular on Regulating the Operation of the Public-Private Partnership Integrated Information Platform (Cai Jin [2015] No.166), establishing the public-private partnership (PPP) Integrated Information Platform and the project library.

The statistics shows that PPP projects number and investment is in a great volume. At the end of September 2016, there have been 10,471 projects included in the PPP Integrated Information Platform, with a total investment of RMB 12.46 trillion; among those projects, 946 were in the process of implementation, with a total investment amounting to RMB 1.56 trillion; 232 were the demonstration projects of the Ministry of Finance, with a total investment of RMB 786.63 billion, including 128 in the process of implementation with a total investment of RMB 345.6 billion. $^{4}$

The green PPP projects have a large room to develop. ${ }^{5}$ Among the projects $^{6}$, municipal engineering projects took lead in terms of number. Among the 128 demonstration projects signed and to be implemented,

\footnotetext{
${ }^{3}$ China scales up green finance system: http://www.eco-business.com/news/china-scales-up-green-finance-system/.

${ }^{4}$ Quarterly Report on the Project Library of the National PPP Integrated Information Platform (No. 4), http://www.cpppc.org/en/Domestic/4286.jhtml, 2016-11-28.

5 Simon Zadek (2015). China's greening of its financial market reform. Retrieved from http://www.chinadaily.com.cn/business/ 2015-03/24/content_19895450.htm

${ }^{6}$ According to the classification, the project library includes projects in 19 primary industries: energy, transportation, water conservancy construction, ecological construction and environmental protection, municipal engineering, area development, agriculture, forestry, science and technology, low-cost housing projects, tourism, medical care and public health, elderly care, education, culture, sports, social security, government infrastructure, and others.
} 
the number of municipal engineering projects was 62 , accounting for $48 \%$; the number of green project including ecological construction and environmental protection projects was 12 , accounting for $9 \%$; the number of water conservancy construction projects is 10 , accounting for $8 \%$. That means the green projects are 22 , only accounting for $17 \%$ all together. Besides, the science and technology projects only accounts for $2 \%$, which provides little power to innovation.

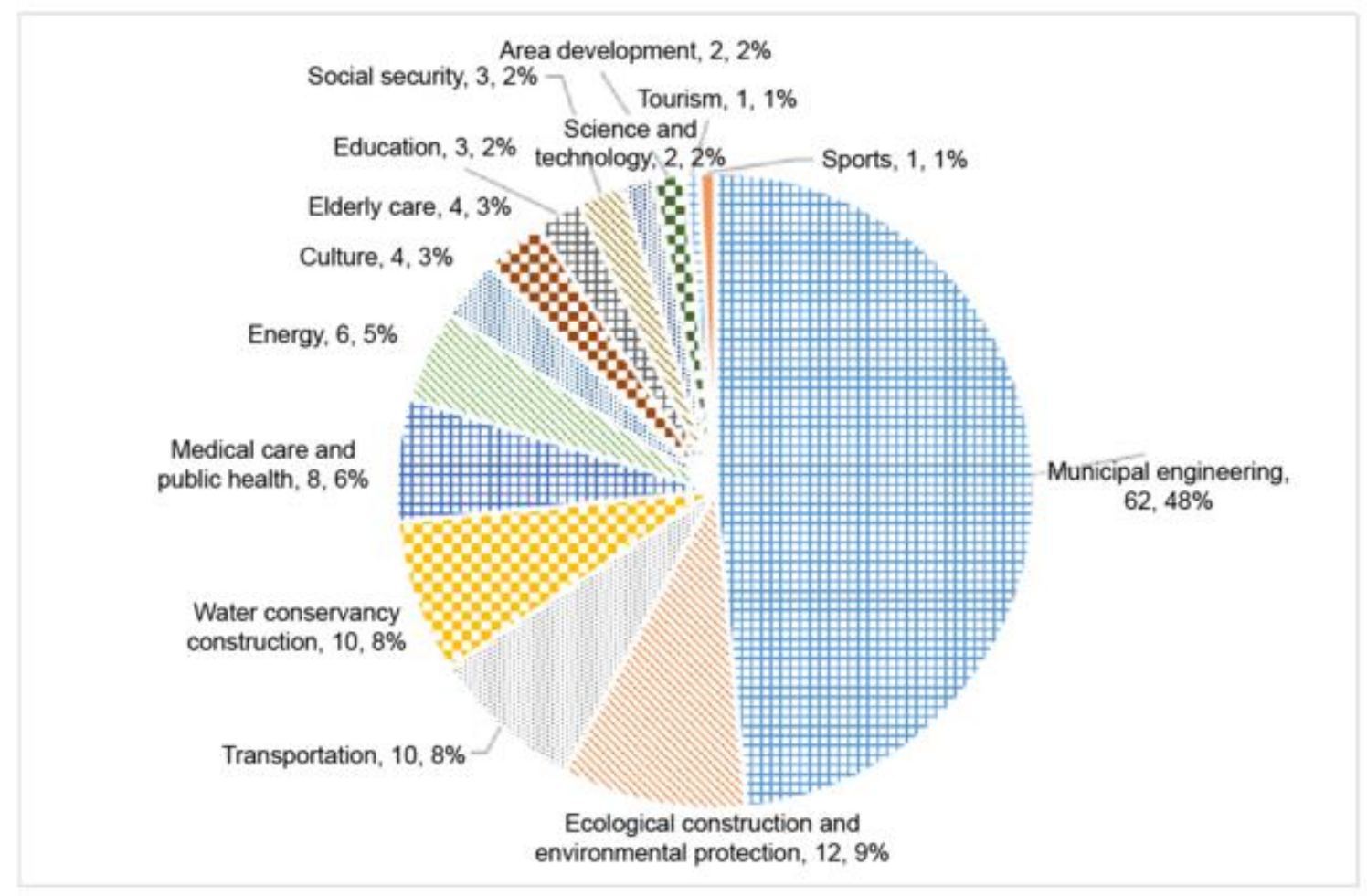

Figure 1. Quarterly report on the Project Library of the National PPP Integrated Information Platform (No. 4).

\section{The Analysis of Green Financing Development in Europe}

Over the past 20 years, the European Union (EU) has often been at the forefront of efforts to build a financial system that supports sustainable development.

First of all, a growing number of social entrepreneurs, mainstream financial institutions, as well as public investment banks have led these efforts. Increasingly, European financial policy-makers and regulators are exploring their role in enabling an orderly transition to a prosperous low-carbon economy. The European Commission (EC) estimates that up to $€ 2$ trillion will be required to meet the policy goals of the Europe 2020 Strategy for smart, sustainable, and inclusive growth. The scale of the investment challenge has prompted a new focus on the strategic role of financial policy and regulation in harnessing the EU financial system. In this context, building a sustainable financial system for Europe countries can contribute to economic recovery by allocating capital to new growth sectors, as well as improving the efficiency and effectiveness of the capital intermediation process through improved risk management, better flows of information, and a core alignment with long-term social purpose. 
Second, as for PPP, Europe also pioneers the trend that may offer helpful experience for China. In the 20 years between 1990 and 2009, there have been more than 1,300 PPP contracts worth more than $€ 5$ million signed within the European Union (EU), at a combined capital value in excess of $€ 250$ billion. The ability of PPPs to provide investment in adverse climates is also demonstrated by the fact that, since 2007, some 350 new projects representing almost $€ 70$ billion have reached financial closure within the EU. Figures suggest that PPP has room to grow and the potential to play an even greater role in future public infrastructure investment. ${ }^{7}$ However, according to the European PPP Expertise Centre, the size of the PPP market in Europe has progressively decreased from around $€ 27$ billion in 2006 to around $€ 15$ billion in 2014 . And this reduction could have been worst without PPP programs, such as the Turkish health program. ${ }^{8}$

\section{EVOLUTION OF EUROPEAN PPPS PER ANNUM}

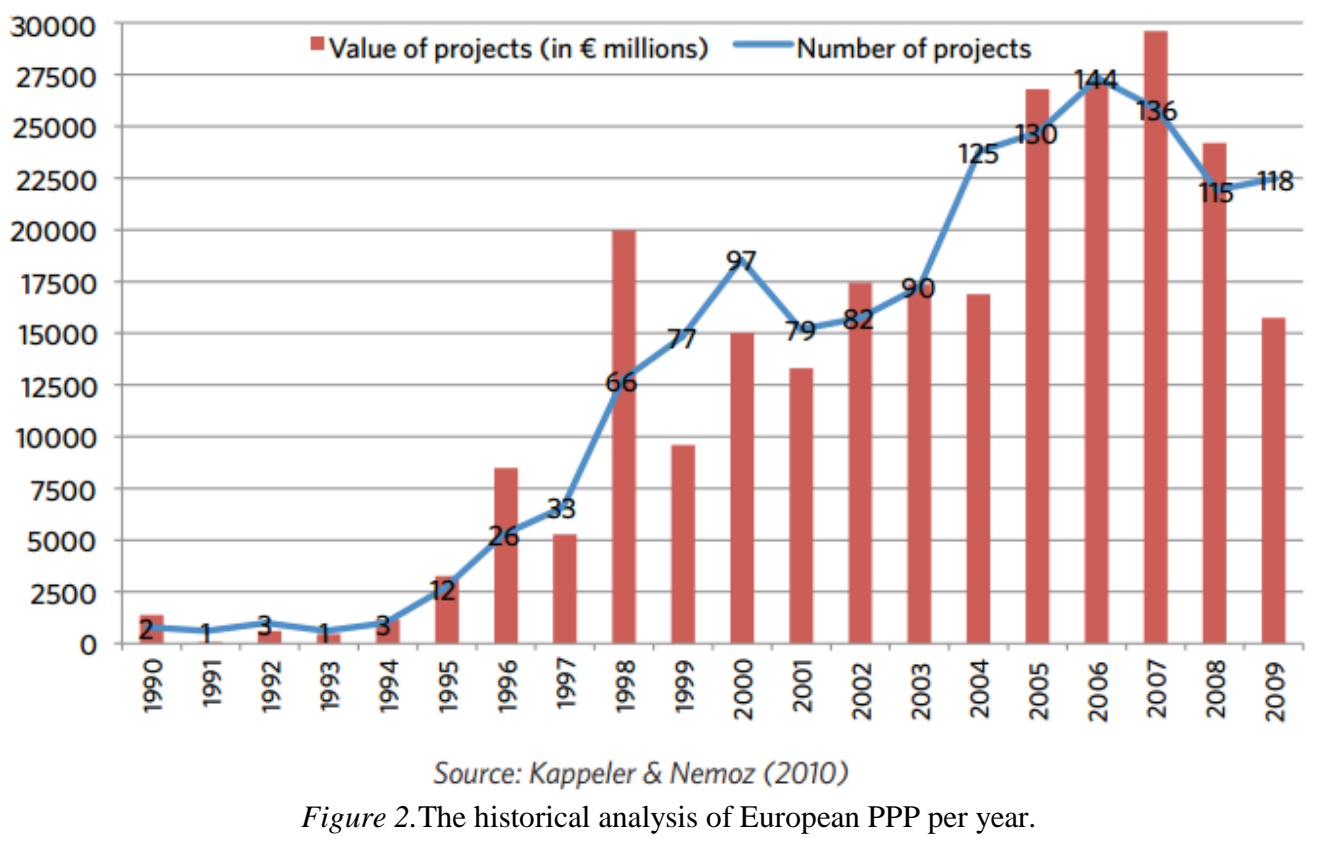

Third, the Europe has formed a comprehensive framework of green financing for sustainable development. The key elements could be summarized as the 5 Rs: reallocating capital, assessing risk, clarifying responsibility, improving reporting, and delivering a strategic reset so that sustainability steers the financial system. The central challenge of financing sustainable development in the EU is one of capital reallocation. Enhancing frameworks for risk management, clarifying the core responsibilities of financial institutions, and improving reporting and disclosure across these dimensions will be necessary to fully unlock flows of sustainable finance. A growing number of Member States are delivering on individual aspects of these priorities, and others are acting within given asset classes. The debate is now advancing to the system level and the need for a strategic reset, seeking to link previously unconnected initiatives and to enhance the capacity of the financial system to support renewed economic competitiveness and improved sustainability performance. ${ }^{9}$

\footnotetext{
7 Oshani Perera: Sustainable Development: Is there a role for public-private partnerships?

${ }^{8}$ Global Outlook PPP Projects 2016, January 2016.

9 United Nations Environment Programme: Building a Sustainable Financial System in the European Union, March 2016.
} 


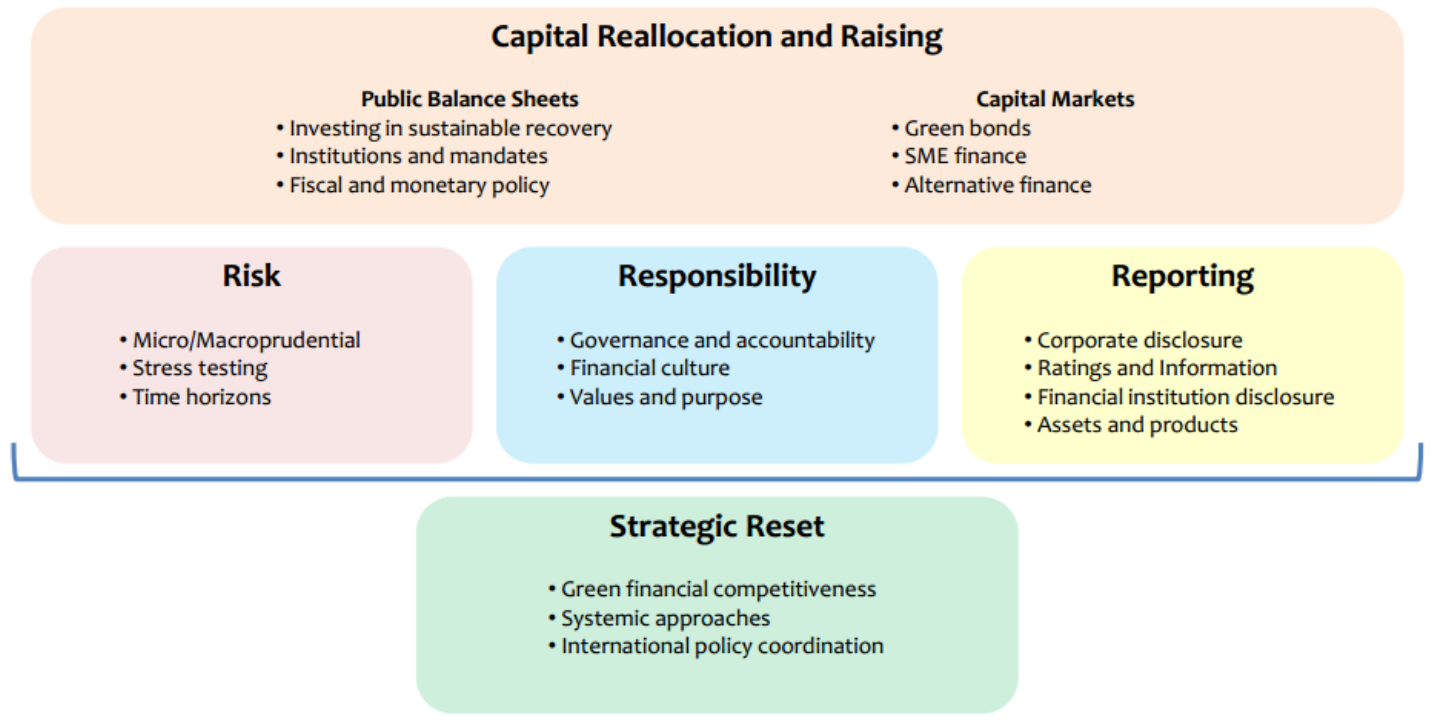

Figure 3. The European framework of green financing for sustainable development.

Reset: Assess strategic challenges and opportunities for the harmonization of existing sustainable finance efforts within the EU and key areas for future work, in order to clarify thinking in advance of broader EC processes on finance through 2016.

Reallocation: harnessing public balance sheets and leveraging public finance institutions, as well as mobilizing Europe's capital markets to enhance sustainable finance, through green bonds, new products, and access to finance for small and medium-size enterprises (SMEs);

Risk: Assessing and managing new dimensions of prudential risks at the institutional and systemic levels;

Responsibility: Strengthening governance and accountability, enhancing financial culture and reaffirming purpose.

\section{The Framework for Cooperation Between Europe and China in Green Financing}

China has made certain progress in the theoretical study and practice of green finance, but there is still a long way to go, ranging from the design of a policy framework and the advocating of the green finance concept to fostering innovative green financial products. That means China is willing to cooperate with other countries and share experience in this domain.

\section{China Needs International Cooperation Frame for Green Economy}

China and the international community need a financial system that effectively and efficiently supports the timely transition to a sustainable and green economy. According to the United Nations Environment Programme, a "green economy" can be defined as one that is low-carbon, resource efficient, and socially inclusive. Globally, investment in infrastructure of an estimated US\$6 trillion annually to 2030 is needed to deliver a low-carbon economy. Of this, nearly US $\$ 1$ trillion is over and above the business-as-usual trajectory, of which China alone will need to raise an additional US\$243 billion annually to 2020. Yet internationally and in China, there is not a comprehensive understanding of a green financial system, covering definitions and standards, institutions, policies, and sequencing for specific contexts.

Green growth is now part of China's development strategy and the demands for green financing keep 
growing as China enters a critical period for economic restructuring. China will establish a green financing mechanism to facilitate the economy's transition to sustainable growth. Supportive policies will promote green financing, such as offering government interest subsidies via refinancing and professional guarantees and setting up national green development fund, which will reduce investors' financing cost or improve their profit. While PPP market in China is booming, China is also facing challenges, such as regulatory issues of PPP market development. When making a choice between speed and quality of PPP market development, China would rather put discipline and quality in the first place.

China's PPP market is interlinked with large international market. China wishes international investors to participate in China's PPP market and share its development achievements. China also encourages Chinese enterprises to take advantage of the PPP model and participate in infrastructure construction and services in foreign countries. In the future, China will further strengthen the cooperation with the World Bank in this field and hope to fully tap the market power to increase the provision of international public service and improve the quality and efficiency of public services.

\section{The Possibility of Cooperation Between Europe and China}

The PPP development in China has shown three notable features that crucial to the cooperation with Europe.

First, China PPP financing has a relative high starting expectation. In the top-level design of PPP, China has fully learned experience and good practices from countries that have a well-developed PPP market, and actively absorbed outcomes in terms of framework setting from international organizations including the World Bank, Asian Development Bank, etc. Based on the national conditions, China has initially built up a 3-in-1 regulatory framework that includes laws, policies, and guidelines, giving full play to the function of consulting agencies, created a sound PPP policy environment and market environment, made efforts to establish a unified, well-regulated, transparent, and efficient PPP market.

Second, China highlights innovation. China has set the strategy of carrying out demonstration projects. China has given full play to the guiding role of demonstration projects, like our lighthouse, and explored a PPP development path that can be replicated, promoted, and amplified. China has encouraged to incorporate more green, low-carbon, and social projects particularly in such fields as low-carbon public transportation, medical care and elderly care, culture and education, etc., so as to guide the economic development model transformation and economic restructuring.

Third, China has a solid foundation in green financing. China has established PPP management institutions at various administrative levels, such as national, provincial, municipal, and county levels. Besides China has set up a national PPP information platform, where all PPP project information is input, managed, and released in a unified fashion from municipal and county level to central level, realizing online supervision and promoting information disclosure. China has provided trainings to various sectors and multiple levels of the government, corporate partners, financial institutions, third-party consulting agencies, etc. China has done extensive publicity via means of WeChat official account, website, etc., to arouse public awareness. The English website of China PPP Center has been officially launched.

\section{The Supposed Cooperation Framework for China and Europe}

In order to support environmentally sustainable growth mutually, it is necessary to make out a framework 
of green financing for both China and Europe. The development of green finance faces a number of challenges, including difficulties in internalizing environmental externalities, maturity mismatch, lacks of clarity in green definitions, information asymmetry and inadequate analytical capacity. According to the China PPP experience, the following factors are the upmost priority to be considered, which share some similarity of that of Europe. Internationally and in China, there is not yet a comprehensive understanding of a green financial system, covering definitions and standards, institutions, policies, and sequencing for specific contexts. This paper focuses on the heated issue of PPP project problems in China, thus proposes a practical framework of cooperation

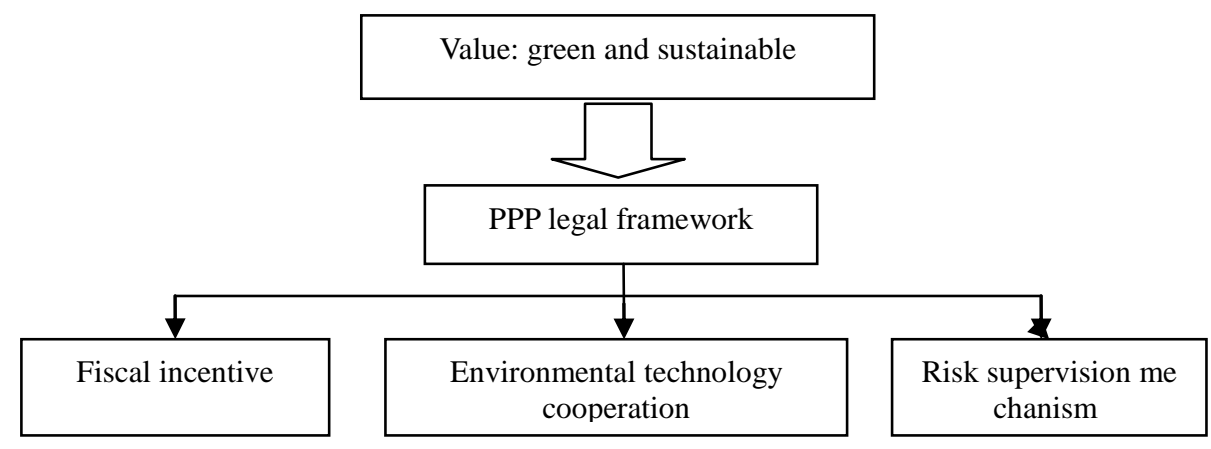

Figure 4. The suggested framework of green financing for both China and Europe.

\section{PPP Legal Cooperation Framework}

A government may decide to enact a PPP law or a concession law for a number of reasons, such as to give priority to a process of developing, procuring, and reviewing PPP projects that will take priority over sector laws, or to establish a clear institutional framework for developing, procuring, and implementing PPPs. PPP laws can also be used to close gaps in the laws of a host country may need to allow for successful infrastructure PPP projects, such as enabling the grant of step-in rights to lenders and requiring open and fair procurement processes. These modifications may be embodied in sector-specific law, or in the case of procurement, a procurement or competition law; or they can be included in a general concession or PPP law.

While guidance and examples can be useful, each PPP law needs careful drafting to be consistent with the host country's existing laws. Legal draftsmen need to strike a balance between setting ground rules that encourage transparency and imposing general restrictions that may hinder bidding teams from achieving value for money or sensible solutions when bidding out PPP projects.

The cooperation of China and Europe is expected to, on the basis of the construction of laws and regulations, share and use the international experience of construction of PPP systems, embodies the top design philosophic value of PPP legislation of China, clarifies relevant basic problems of PPP legislation, and puts forward solutions and routes for actual legal conflicts and barriers, such as contract attribute, settlement of disputes, land acquisition, and asset ownership during the operation of PPP projects in China.

\section{Fiscal Incentives}

Taxation ranks among the most prominent tools in the context of environmental and sustainability objectives. The majority of environmental tax incentives focus on downstream investment decisions for governments, households, and companies, including environmental duties on retail electricity, transport fuels and emissions. To date, opportunities for linking tax incentives within the financial system to sustainability 
objectives have been relatively under explored. One area of potential alignment is the body of tax incentives focused on individual consumers, including tax incentives for savers and retail investors. By providing tax exemptions to retail investors, savers' capital can potentially be steered towards specific investments, in particular green sectors or SMEs. A notable example of national-level innovation is France, where different incentive mechanisms are used to steer the allocation of savings to specific socially oriented funds.

\section{Environmental Technology Cooperation}

China also plays a significant role in limiting carbon emissions throughout the world. China's One Belt, One Road (OBOR) initiative aims to connect major economies among 60 countries in Asia, Africa, and Europe. It is essential that OBOR implements guidelines for green finance to greatly mitigate potential carbon emissions from new projects. Besides China's top legislature on Saturday adopted an amendment to the Air Pollution Control Law that will restrict various sources of smog and make information on environmental cleanliness more readily available to the public. However, China is lack of many cost-effective technology of air and water pollution control. The wastewater and sewage disposal has been major threat to human health in China. The liquid waste discharged by domestic residences, commercial properties, industry, or agriculture generates potential contaminants and concentrations that to some extent is minimized or recycled in the developed world. It necessitates the adoption of available and affordable technology for renewable energy including sunlight, wind, rain, and geothermal heat, which are naturally replenished. The technologies that are available are solar power, wind power, hydroelectricity/micro hydro, biomass, and biofuels for transport.

\section{Risk Supervision Mechanism}

China is eager to improve the supervision mechanism to prevent risks related to green finance. China plans to improve coordination among supervisory agencies on green finance businesses and products, make comprehensive use of macro-prudential and micro-prudential management tools, unify relevant supervision rules and standards, enhance information disclosure, effectively control the default risks of green loans and green bonds, and fully develop equity finance, with a view to preventing excessive leverage by green projects, unhealthy financial arbitrage, "greenwashing" and other problems, and preventing systematic financial risks.

\section{Conclusion}

All in all, Chinese government considers PPP as a major mechanism and institutional reform to help modernize the state governance capacity, give play to the decisive role of the market in resource allocation, accelerate the transformation of government functions, administer the country under the rule of law, and proactively and steadily promote the PPP model in respect of top-level design, institutional establishment, and project demonstration, striving to build a unified and well-regulated PPP market, and preliminary results have been achieved. In the future, the PPP Centre will strengthen the cooperation with Asian Development Bank (ADB) and other international organizations, input more efforts in enhancing institutional capacity, innovate the ways to support the financing for PPP projects, and improve the government's risk identification and management capabilities to facilitate the implementation of PPP policies and projects. With the close cooperation with European countries that have abundant experience, China and Europe may establish a green and sustainable new model of economic development that helpful for the world economic recovery.

\section{References}

China Green Finance Task Force. (2015). Establishing China's Green Financial System, China Finance Publishing. Retrieve from http://www.unep.org/newscentre/default.aspx? DocumentID=26802\&ArticleID=34981 
IFC. (2013). Mobilizing Public and Private Funds for Inclusive Green Growth Investment in Developing Countries - An Expanded Stocktaking Report Prepared for the G20 Development Working Group. IFC Climate Business Department.

McDaniels, J., Robins, N., Strauss, D., Thomä, J., \& Dupré, S. (2016). Building a Sustainable Financial System in the European Union. Retrieved from www.unep.org/inquiry

Medland, D. (2016). A Quiet Revolution' On Green Finance With China Taking The Lead. Retrieved from http://www.forbes.com/sites/dinamedland/2016/09/10/a-quiet-revolution-on-green-finance-with-china-taking-the-lead/\#24ad 46e 44 cbe

Spratt \& Jones, G. (2013). Mobilising Investment for Inclusive Green Growth in Low-Income Countries. GIZ.

Steiner, A. (2016). Why Sustainable Finance Holds the Key to Europe's Recovery. Retrieved from https://www.euractiv.com/section/climate-environment/opinion/why-sustainable-finance-holds-the-key-to-europes-recovery/ 